\title{
Development of a method for profiling of volatile organic compounds to monitor heat stress in hot water dipped apples
}

\author{
M. Himmelboe ${ }^{1, a}$, A. Luca ${ }^{1}$, R. de Paulo Rocha ${ }^{2}$, M.G. Bertelsen ${ }^{1}$ and M. Edelenbos ${ }^{1}$ \\ 1Department of Food Science, Aarhus University, Kirstinebjergvej 10, 5792 Årslev, Denmark; ${ }^{2}$ Departamento de \\ Ciência dos Alimentos, Federal University of Lavras, 37200-000 Lavras, MG, Brazil.
}

\begin{abstract}
Storage rot is a major contributor to losses of organic apples due to restrictions in spraying in orchards. Postharvest pre-treatments such as hot water dipping (HWD) have been proven successful to reduce storage rot. However, excessive heat during dipping easily induces heat stress and physiological disorders, which only show up after several weeks of cold storage. To develop further the HWD technology, a method for early detection of physiological disorders is desirable. As apples emit volatile organic compounds (VOCs) in response to stress and ripening, VOC profiling can be a useful tool for detecting the immediate heat stress and latent physiological disorders. In this study, a selected ion-monitoring program was developed for analyzing VOCs from apples (Malus domestica 'Ingrid Marie' and 'Pinova') dipped in water at 20 and $56^{\circ} \mathrm{C}$ for $3 \mathrm{~min}$. VOCs were sampled by solid-phase microextraction and analyzed by GC-MS in total ion current mode. From these results, a selected ion-monitoring program was developed which enabled detection of trace VOCs collected by static headspace sampling. The results showed that all apples dipped in $56^{\circ} \mathrm{C}$ for $3 \mathrm{~min}$ developed visual signs of physiological disorders in cold storage. At the same time, the VOC profile of these apples differed from that of the $20^{\circ} \mathrm{C}$ treated apples. This work provides a solid basis for a future development of the VOC method to forecast physiological disorders and to improve the HWD technology for better control of storage rot.
\end{abstract}

Keywords: hot water dipping, physiological disorders, GC-MS, VOCs, static headspace sampling, solid-phase microextraction

\section{INTRODUCTION}

Research on organic production is becoming more important due to increasing consumer awareness towards the impact of pesticide application on the environment and on food safety. One of the main problems in organic apple production is the low yield of first class apples. Higher incidences of pest insects and diseases in the orchard result in smaller and irregular fruits (Pedersen, 2012). The yield of organic apples in Sweden has thus been reported to be almost half of the yield of conventional production (Ascard et al., 2010). Of the abovementioned factors, fungal infections are the most damaging factor causing yield reductions in orchards and during storage. Although most storage rots are already present as latent infections before harvest, the symptoms are often delayed until storage. Thus, a large proportion of the organic crop is lost after harvest due to development of storage rot caused by pathogenic fungi. As conventional fungicides are not allowed, there is a need for ecofriendly alternatives that are able to reduce storage rot in organic apple production.

Hot water dipping (HWD) is one of the most effective postharvest pre-treatments to control storage rot in apples. In northern Germany, HWD has proved to be effective against storage rots in apples with efficacies above 80\% (Maxin et al., 2012a). HWD also reduces chilling injuries, delays ripening processes (Fallik, 2004), and controls pest insects (Smith and Lay-Yee, 2000). However, caution must be taken as excessive heat can cause heat stress

${ }^{a}$ E-mail: himmelboe@food.au.dk 
and development of physiological disorders. Maxin et al. (2012b) found that the apple cultivar 'Elstar' developed physiological disorders when the fruit were dipped in hot water at temperatures above $53^{\circ} \mathrm{C}$ for $3 \mathrm{~min}$. Browning of the peel, flesh darkening, pitting, elevated decay and earlier fruit softening are common symptoms of physiological disorders in hot water treated fruits (Lurie, 1998). As these symptoms do not show up until several weeks after treatment, new methods for early detection of physiological disorders are needed.

Apples produce a variety of volatile organic compounds (VOCs) during ripening (Fellman et al., 2003) and in response to multiple biotic (Llusià and Peñuelas, 2001; López et al., 2015; Spinelli et al., 2011) and abiotic stresses (Ebel et al., 1995; Vallat et al., 2005). VOC profiling might thus be a useful tool for the detection of heat stress in apples due to HWD. Several techniques have been developed for sampling of VOCs. Static headspace sampling (SHS) is by far the simplest method but the method lacks sensitivity. However, the sensitivity can be greatly improved by analyzing the gas samples in selected ion monitoring (SIM) mode. However, this requires that relevant compounds are included in the SIM program. To make a library of compounds and build the SIM program, the more sensitive, although time consuming, solid-phase microextraction (SPME) can be used (Luca et al., 2015).

The aim of this study was to develop a method for VOC profiling of hot water dipped apples as a tool for early detection of heat stress and development of physiological disorders during cold storage. The developed method is based on static headspace samples which are analyzed by GC-MS using a SIM program.

\section{MATERIALS AND METHODS}

\section{Fruit}

Apples (Malus domestica 'Ingrid Marie' and 'Pinova') were harvested from Aarhus University's orchard in Årslev. Only blemish free fruit were selected. The fruit were stored at $2^{\circ} \mathrm{C}$ until the day before HWD when they were moved to room temperature to acclimate overnight.

\section{Hot water dipping}

A plastic tank was filled with tap water and heated to 20 or $56^{\circ} \mathrm{C}$ before the apples were dipped. For dipping, the apples were placed in one box with an additional empty box on top to prevent apples from floating. The two boxes were submerged into the water for 3 min. The box containing the apples were then moved to a drying cabinet (Lytzen A/S, Herlev, Denmark) for $25 \mathrm{~min}$ at $24^{\circ} \mathrm{C}$ before it was moved to cold storage for 14 weeks at $2^{\circ} \mathrm{C}$.

\section{VOC analysis and assessment of physiological disorders}

From each treatment, three 2-L jars were prepared, each with 5 apples with a combined weight of $900 \mathrm{~g}$. The jars were closed with lids equipped with a septum for gas sampling and moved to climate chambers at $20^{\circ} \mathrm{C}$. The remaining apples were moved to cold storage at $2^{\circ} \mathrm{C}$ and evaluated for visual physiological disorders after 8 and 14 weeks.

\section{Solid-phase microextraction}

To generate a broad list of VOCs emitted from the apples, the compounds were sampled by SPME after approximately $3 \mathrm{~h}$ of incubation from one jar of each combination of cultivar and treatment using a carboxen/polydimethylsiloxane fiber, which was exposed in the headspace for $5 \mathrm{~min}$.

Separation of compounds was performed on an Agilent 7890A GC equipped with a HPPLOT/Q (Agilent Technologies, Palo Alto, CA, USA) column (30 m $\times 320 \mu \mathrm{m} \times 20 \mu \mathrm{m})$. The GC was held at constant pressure (2.1215 psi) giving a flow of $1 \mathrm{~mL} \mathrm{~min}^{-1}$ using He as carrier gas. The SPME fiber was thermally desorbed in the injection port in splitless mode at $200^{\circ} \mathrm{C}$ for $1 \mathrm{~min}$. The oven temperature was initially held at $30^{\circ} \mathrm{C}$ for $1 \mathrm{~min}$ followed by heating to $250^{\circ} \mathrm{C}$ at $20^{\circ} \mathrm{C} / \mathrm{min}$ and then kept at this temperature for $18 \mathrm{~min}$. The fiber was reconditioned at $250^{\circ} \mathrm{C}$ for approximately $20 \mathrm{~min}$ after desorption. 
The compounds were identified on an Agilent 5975C inertXL mass selective detector (Agilent Technologies, USA) operating in total ion current mode using electron ionization at $70 \mathrm{eV}$. Mass-to-charge ratios between 20 and 200 were scanned using a quadropole mass analyzer. Compounds suggested by the NIST/EPA/NIH Mass Spectral Database were verified by comparison of retention indices and mass spectra of authentic reference compounds when available.

A SIM program was constructed (Table 1) from the list of compounds generated using the SPME sampling procedure. The compounds were divided into 17 groups depending on retention time. Within each group, each compound were designated a target ion based on the purity of the individual peaks. In order to further validate the identity of compounds in Table 1, 1-2 additional qualifier ions were designated. Dwell time was set to $50 \mathrm{~ms}$ for target ions and $10 \mathrm{~ms}$ for qualifier ions.

Table 1. Full list of volatile organic compounds identified from hot water dipped apples using solid-phase microextraction sampling analyzed on GC-MS in total ion current mode. From this, a selected ion-monitoring (SIM) program was generated. Volatile organic compounds detected in the static headspace samples using this SIM program are also shown.

\begin{tabular}{|c|c|c|c|c|c|c|}
\hline \multirow[b]{2}{*}{$\begin{array}{l}\text { RT } \\
(\min )\end{array}$} & \multirow[b]{2}{*}{ Compound name ${ }^{1}$} & \multicolumn{4}{|c|}{ SIM program² } & \multirow[b]{2}{*}{ Detected by SHS } \\
\hline & & $\begin{array}{l}\text { Start } \\
(\mathrm{min})\end{array}$ & $\begin{array}{c}\text { Target ion } \\
(\mathrm{m} / \mathrm{z})\end{array}$ & $\begin{array}{c}\text { Q1 } \\
(\mathrm{m} / \mathrm{z})\end{array}$ & $\begin{array}{c}\text { Q2 } \\
(\mathrm{m} / \mathrm{z})\end{array}$ & \\
\hline 7.18 & Methanol & 6.50 & 32 & 31 & & + \\
\hline 7.27 & Acetaldehyde & & 43 & 29 & & + \\
\hline 8.07 & 2-Methylpropene 3 & 7.70 & 41 & 56 & 39 & + \\
\hline 8.66 & Ethanol & 8.30 & 31 & 45 & 46 & + \\
\hline 9.15 & Prop-2-enal ${ }^{3}$ & 9.00 & 56 & 55 & 26 & \\
\hline 9.31 & Propanal & & 58 & 29 & & + \\
\hline 9.42 & Acetone & & 43 & 58 & & + \\
\hline 9.47 & Methanedithione & & 76 & 78 & & \\
\hline 9.54 & Methylthiomethane & & 47 & 62 & & + \\
\hline 9.76 & Methyl acetate & & 43 & 74 & & + \\
\hline 10.06 & Pentane & 9.90 & 43 & 42 & 41 & + \\
\hline 10.41 & Propan-1-o| ${ }^{3}$ & 10.20 & 31 & 59 & & + \\
\hline 10.63 & 2-Methylpropanal & & 72 & 43 & & + \\
\hline 10.85 & 2-Methylfuran & & 82 & 81 & & \\
\hline 10.96 & Butanal & & 41 & 43 & & + \\
\hline 10.98 & 3-Methylfuran & & 82 & 81 & & + \\
\hline 11.02 & Butan-2-one & & 43 & 72 & & + \\
\hline 11.14 & Ethyl acetate & & 43 & 61 & & + \\
\hline 11.26 & Methyl propanoate 3 & & 57 & 88 & & \\
\hline 11.63 & 1-Methoxybutane 3 & 11.50 & 45 & 56 & & \\
\hline 11.92 & Butan-1-ol & 11.75 & 56 & 43 & & \\
\hline
\end{tabular}

${ }^{1}$ Compounds were identified by library search (NIST/EPA/NIH Mass Spectral Database) and validated by comparing retention time (RT) and mass spectra to those of authentic gas samples.

${ }^{2}$ SIM program constructed from the list of compounds generated using a solid-phase microextraction sampling procedure. The program was used to analyze volatile organic compounds from samples collected by static headspace sampling (SHS). Dwell time were $50 \mathrm{~ms}$ for target ions and $10 \mathrm{~ms}$ for qualifier ion 1 and 2 (Q1 and Q2).

${ }^{3}$ Only tentative identified from library search. 
Table 1. Continued.

\begin{tabular}{|c|c|c|c|c|c|c|}
\hline \multirow[b]{2}{*}{$\begin{array}{l}\text { RT } \\
\text { (min) }\end{array}$} & \multirow[b]{2}{*}{ Compound name ${ }^{1}$} & \multicolumn{4}{|c|}{ SIM program ${ }^{2}$} & \multirow[b]{2}{*}{ Detected by SHS } \\
\hline & & $\begin{array}{l}\text { Start } \\
(\mathrm{min})\end{array}$ & $\begin{array}{c}\text { Target ion } \\
(\mathrm{m} / \mathrm{z})\end{array}$ & $\begin{array}{c}\text { Q1 } \\
(\mathrm{m} / \mathrm{z})\end{array}$ & $\begin{array}{c}\text { Q2 } \\
(\mathrm{m} / \mathrm{z})\end{array}$ & \\
\hline 12.14 & 2-Methylbutanal ${ }^{3}$ & & 58 & 57 & & \\
\hline 12.36 & 2-Pentanone 3 & & 86 & 71 & & \\
\hline 12.46 & Ethyl propanoate & & 102 & 57 & & \\
\hline 12.53 & Propyl acetate 3 & & 61 & 73 & & + \\
\hline 12.61 & Methyl butanoate & & 71 & 74 & & \\
\hline 12.65 & 1-Methoxy-2-methylbutane 3 & & 45 & 70 & & + \\
\hline 13.21 & 2-Methyl-1-butanol & 12.90 & 57 & 41 & & + \\
\hline 13.50 & Ethyl 2-methylpropanoate 3 & & 43 & 71 & & \\
\hline 13.75 & 2-Methylpropyl acetate ${ }^{3}$ & & 43 & 73 & & + \\
\hline 14.02 & Ethyl butanoate ${ }^{3}$ & & 88 & 43 & & + \\
\hline 14.09 & Propyl propanoate ${ }^{3}$ & & 75 & 57 & & + \\
\hline 14.22 & Butyl acetate $^{3}$ & & 61 & 73 & & + \\
\hline 14.58 & Butanoic acidc & 14.35 & 60 & 73 & & \\
\hline 15.52 & Ethyl 2-methylbutanoate & 15.10 & 102 & 85 & & \\
\hline 15.62 & Hexan-1-ol & & 43 & 56 & & \\
\hline 15.87 & 2-Methylpropyl propanoate 3 & & 57 & 29 & & \\
\hline 16.10 & 2-Methylbutyl acetate ${ }^{3}$ & & 70 & 43 & & + \\
\hline 16.42 & Propyl butanoate ${ }^{3}$ & & 89 & 43 & & \\
\hline 16.59 & Butyl propanoate 3 & & 75 & 56 & & + \\
\hline 16.78 & Pentyl acetate ${ }^{3}$ & & 61 & 70 & & \\
\hline 18.97 & Propyl 2-methylbutanoate ${ }^{3}$ & 17.50 & 85 & 57 & & + \\
\hline 19.08 & Butyl 2-methylpropanoate 3 & & 71 & 89 & & \\
\hline 19.34 & 2-Methylpropyl butanoate 3 & & 71 & 43 & & \\
\hline 19.68 & 1-Methylbutyl propanoate 3 & & 57 & 70 & & \\
\hline 19.92 & 6-Methyl-5-heptene-2-one & & 108 & 41 & & \\
\hline 20.53 & Butyl butanoate ${ }^{3}$ & 20.25 & 89 & 71 & & \\
\hline 20.80 & 3-Methylbutyl propanoate 3 & & 57 & 70 & & \\
\hline 21.23 & Hexyl acetate & & 43 & 56 & & + \\
\hline 24.87 & Butyl 2-methylbutanoate ${ }^{3}$ & 24.40 & 57 & 103 & & \\
\hline 25.85 & 2-Methylbutyl butanoate 3 & 25.30 & 71 & 43 & & \\
\hline 27.81 & Propyl hexanoate ${ }^{3}$ & 26.50 & 99 & 43 & 61 & \\
\hline 28.36 & Hexyl propanoate ${ }^{3}$ & & 75 & 57 & 56 & \\
\hline Termin & ation of program after $29.10 \mathrm{~m}$ & & & & & \\
\hline
\end{tabular}

\section{Static headspace sampling}

A 2.4-mL headspace sample was taken with a gastight syringe from each jar after $2 \mathrm{~h}$ of incubation into a $3.0 \mathrm{~mL}$ depressurized, flat-bottomed soda glass vial (Labco Limited, Lampeter, UK) sealed with a double septum consisting of rubber and Teflon/silicon. The vials were stored at $-80^{\circ} \mathrm{C}$ until GC-MS analysis.

Separation of VOCs was performed on the abovementioned GC-MS, using the same column and flow rate. From each vial, a gas sample of $500 \mu \mathrm{L}$ was automatically withdrawn using a Combi PAL autosampler (CTC Analytics AG, Zwingen, Switzerland) and injected into the GC inlet in a 3:1 split ratio. Oven temperature was initially held at $30^{\circ} \mathrm{C}$ for $1 \mathrm{~min}$ followed by heating to $250^{\circ} \mathrm{C}$ at $20^{\circ} \mathrm{C} \mathrm{min}-1$ and kept at this temperature for $18 \mathrm{~min}$. All compounds were identified by MS operating in SIM mode (70 eV) as described in Table 1. 


\section{RESULTS AND DISCUSSION}

Apples treated with HWD at $56^{\circ} \mathrm{C}$ for 3 min showed signs of physiological disorders at weeks 8 and 14, respectively. Apples treated with $\mathrm{HWD}$ at $20^{\circ} \mathrm{C}$ for 3 min displayed no signs of physiological disorders. This is consistent with earlier findings that treatment with $53^{\circ} \mathrm{C}$ or warmer water for 3 min resulted in physiological disorders in 'Elstar' apples (Maxin et al., 2012b).

Sampling of VOCs using SPME resulted in the detection of 53 compounds when analyzed in total ion current mode. Based on this list, a SIM method was developed (Table 1) which was then used for the analysis of the static headspace samples. A total of 27 VOCs were identified in the static headspace samples using this SIM program.

\section{VOCs associated with low temperature HWD}

The esters were by far the largest group of compounds found in the static headspace samples (Table 1). These are important aroma compounds responsible for the fruity aromas of apples. Some of the esters, like butyl butanoate and hexyl acetate, were produced in higher quantities by both cultivars of apples treated with water at low temperature (Figure 1A). 'Ingrid Marie' also produced more butyl acetate at the low temperature but the same behavior was not observed for 'Pinova' (Figure 1B). This result underlines the importance of using more than one cultivar when developing a VOC based method to detect the immediate heat stress response in hot water dipped apples, especially if the method is to be applied on apples in general.

\section{VOCs associated with high temperature HWD}

The production of acetaldehyde was strongly linked to the high temperature HWD $\left(56^{\circ} \mathrm{C}\right)$ of both apple cultivars (Figure $1 \mathrm{C}$ ). Besides being released from plants as a result of fermentation reactions (Kozlowski and Pallardy, 2002; Kreuzwieser et al., 2001) acetaldehyde emission has also been linked to stress factors such as wounding, high intensity light and high temperature exposure (Loreto et al., 2006). Methanol was also produced in higher concentrations following high temperature HWD (Figure 1C). The source of methanol is most likely from demethylation of the pectin in the cell walls and middle lamellas (Galbally and Kirstine, 2002). A slight increase in the emission of acetone was observed in apples treated with high temperature HWD (Figure 1D). Acetone could be produced by fatty acid oxidation leading to acetoacetic acid and a spontaneous decarboxylation into acetone (Murphy, 1985). As all of these VOCs originate from universal metabolic processes, these compounds could possibly be used as biomarkers of heat stress response in various fresh produce subjected to HWD. Methylpropene also appears to be linked to apples treated at high temperature (Figure 1E). The existing literature offers no explanation as to the origin. However, as indicated in Table 1 the compound's identity has yet to be confirmed by a known standard. 

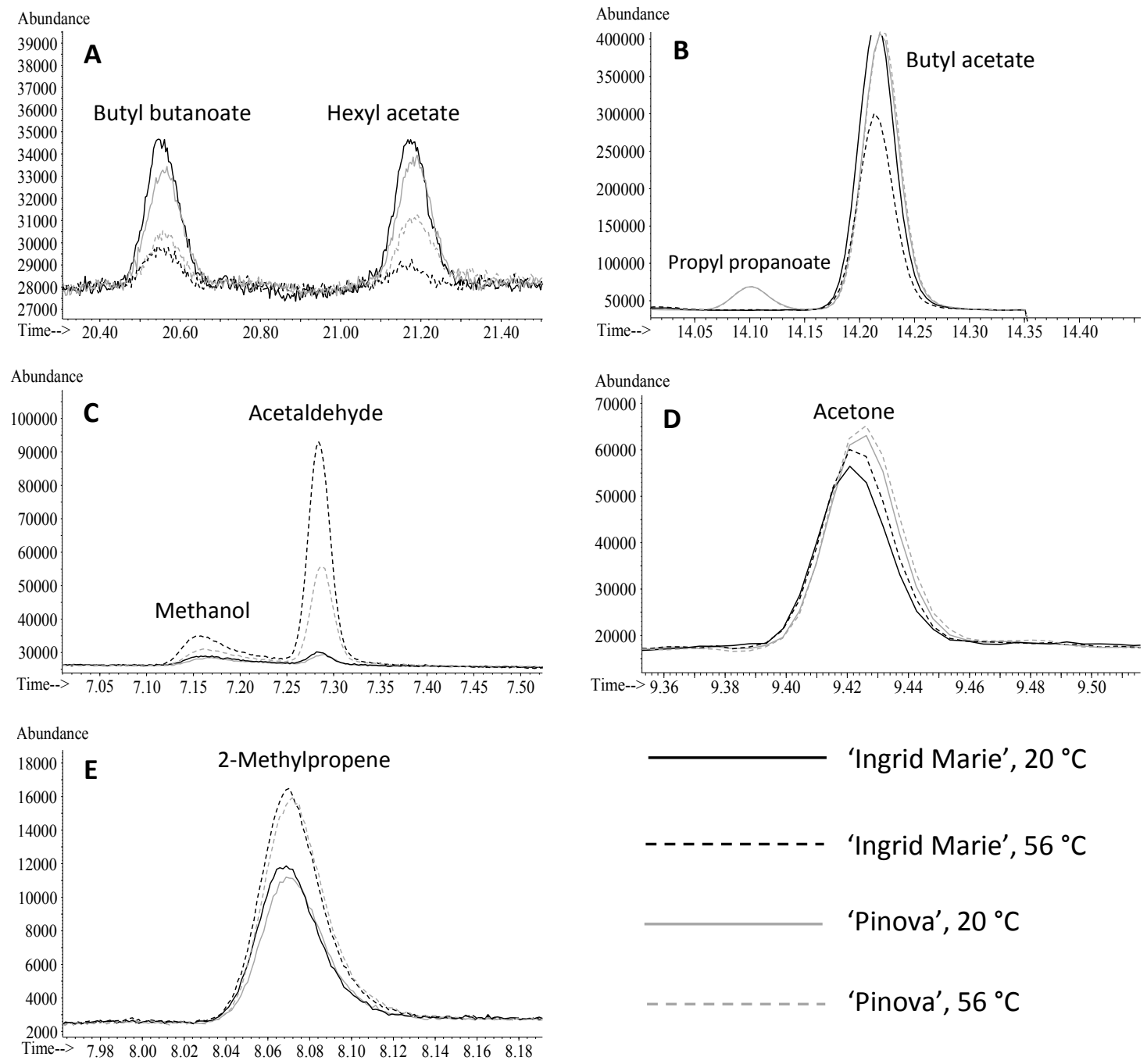

Figure 1. Selected volatile organic compounds produced by apples of the cultivars 'Ingrid Marie' and 'Pinova' treated with 20 and $56^{\circ} \mathrm{C}$ water for $3 \mathrm{~min}$. The results were obtained using static headspace sampling in combination with GC-MS running in selected ion-monitoring mode.

\section{CONCLUSIONS}

A method for VOC profiling of hot water dipped apples based on SHS and analysis of compounds on GC-MS in SIM mode was developed. Several compounds were either characteristic for low temperature (butyl butanoate and hexyl acetate) or high temperature (acetaldehyde, methanol, and acetone) HWD of apples. These results show that the developed VOC profiling method could be a useful tool for early detection of heat stress response in apple due to HWD. Future studies on HWD should include a range of temperatures to find out the relations between VOCs and latent physiological disorders.

\section{ACKNOWLEDGEMENTS}

The project PROTECFRUIT is part of the Organic RDD 2 program, which is coordinated by the International Centre for Research in Organic Food Systems (ICROFS). The project has received a grant from the Green Growth and Development program (GUDP) under the Danish Ministry of Food, Agriculture and Fisheries. 


\section{Literature cited}

Ascard, J., Hansson, A., Håkansson, B., Stridh, H. and Söderlind, M. (2010). Ekonomi i fruktodling - Kalkyler för äpple.

Ebel, R.C., Mattheis, J.P., and Buchanan, D.A. (1995). Drought stress of apple-trees alters leaf emissions of volatile compounds. Physiol. Plant. 93 (4), 709-712 http://dx.doi.org/10.1111/j.1399-3054.1995.tb05120.x.

Fallik, E. (2004). Prestorage hot water treatments (immersion, rinsing and brushing). Postharvest Biol. Technol. 32 (2), 125-134 http://dx.doi.org/10.1016/j.postharvbio.2003.10.005.

Fellman, J.K., Rudell, D.R., Mattinson, D.S., and Mattheis, J.P. (2003). Relationship of harvest maturity to flavor regeneration after CA storage of 'Delicious' apples. Postharvest Biol. Technol. 27 (1), 39-51 http://dx.doi.org/ 10.1016/S0925-5214(02)00193-X.

Galbally, I.E., and Kirstine, W. (2002). The production of methanol by flowering plants and the global cycle of methanol. J. Atmos. Chem. 43 (3), 195-229 http://dx.doi.org/10.1023/A:1020684815474.

Kozlowski, T.T., and Pallardy, S.G. (2002). Acclimation and adaptive responses of woody plants to environmental stresses. Bot. Rev. 68 (2), 270-334 http://dx.doi.org/10.1663/0006-8101(2002)068[0270:AAAROW]2.0.CO;2.

Kreuzwieser, J., Harren, F.J.M., Laarhoven, L.J.J., Boamfa, I., Te Lintel-Hekkert, S., Scheerer, U., Hüglin, C., and Rennenberg, H. (2001). Acetaldehyde emission by the leaves of trees - correlation with physiological and environmental parameters. Physiol. Plant. 113 (1), 41-49 http://dx.doi.org/10.1034/j.1399-3054.2001. 1130106.x.

Llusià, J., and Peñuelas, J. (2001). Emission of volatile organic compounds by apple trees under spider mite attack and attraction of predatory mites. Exp. Appl. Acarol. 25 (1), 65-77. PubMed http://dx.doi.org/10.1023/ A:1010659826193

López, L., Echeverria, G., Usall, J., and Teixido, N. (2015). The detection of fungal diseases in the 'Golden Smoothee' apple and 'Blanquilla' pear based on the volatile profile. Postharvest Biol. Technol. 99, 120-130 http://dx.doi. org/10.1016/j.postharvbio.2014.08.005.

Loreto, F., Barta, C., Brilli, F., and Nogues, I. (2006). On the induction of volatile organic compound emissions by plants as consequence of wounding or fluctuations of light and temperature. Plant Cell Environ. 29 (9), 18201828. PubMed http://dx.doi.org/10.1111/j.1365-3040.2006.01561.x

Luca, A., Bach, V., and Edelenbos, M. (2015). Optimization of headspace solid-phase microextraction and static headspace sampling of low-boiling volatiles emitted from wild rocket (Diplotaxis tenuifolia L.). Food Anal. Methods 8 (5), 1185-1196 http://dx.doi.org/10.1007/s12161-014-9993-5.

Lurie, S. (1998). Postharvest heat treatments. Postharvest Biol. Technol. 14 (3), 257-269 http://dx.doi.org/ 10.1016/S0925-5214(98)00045-3.

Maxin, P., Weber, R.W.S., Pedersen, H.L., and Williams, M. (2012a). Control of a wide range of storage rots in naturally infected apples by hot-water dipping and rinsing. Postharvest Biol. Technol. 70, 25-31 http://dx.doi. org/10.1016/j.postharvbio.2012.04.001.

Maxin, P., Weber, R.W.S., Pedersen, H.L., and Williams, M. (2012b). Hot-water dipping of apples to control Penicillium expansum, Neonectria galligena and Botrytis cinerea: effects of temperature on spore germination and fruit rots. Eur. J. Hortic. Sci. 77, 1-9.

Murphy, J.B. (1985). Acetone production during the germination of fatty seeds. Physiol. Plant. 63 (2), 231-234 http://dx.doi.org/10.1111/j.1399-3054.1985.tb01908.x.

Pedersen, B.A. (2012). Udfordringer med dyrkning af økologiske æbler (Økologisk Landsforening).

Smith, K.J., and Lay-Yee, M. (2000). Response of 'Royal Gala' apples to hot water treatment for insect control. Postharvest Biol. Technol. 19 (2), 111-122 http://dx.doi.org/10.1016/S0925-5214(00)00088-0.

Spinelli, F., Costa, G., Rondelli, E., Busi, S., Vanneste, J.L., Rodriguez, E.M.T., Savioli, S., Harren, F.J.M., Crespo, E., and Cristescu, S.M. (2011). Emission of volatiles during the pathogenic interaction between Erwinia amylovora and Malus domestica. Acta Hortic. 896, 55-63 http://dx.doi.org/10.17660/ActaHortic.2011.896.5.

Vallat, A., Gu, H., and Dorn, S. (2005). How rainfall, relative humidity and temperature influence volatile emissions from apple trees in situ. Phytochemistry 66 (13), 1540-1550. PubMed http://dx.doi.org/10.1016/ j.phytochem.2005.04.038 
